\title{
Caso Motivador como Estratégia Problematizadora e Integradora no Ensino Médico em um Curso de Oncologia
}

\author{
The Motivational Case as an Integrative Problem- \\ Solving Strategy in Oncology Medical Teaching
}

Paula O M Hokama

Newton Key Hokama ${ }^{I}$

Nildo Batista ${ }^{I I}$

\section{PALAVRAS-CHAVE}

- Motivação.

- Oncologia.

- Aprendizagem Ativa.

- Educação Médica.
I Universidade Estadual Paulista, Botucatu, São Paulo, Brasil.

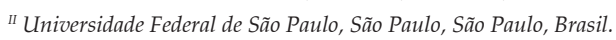

\begin{abstract}
RESUMO
Caso Motivador, também denominado situação-problema ou case study, é uma metodologia centrada no aluno, problematizadora, de ensino-aprendizagem, que permite conhecer os saberes prévios do grupo frente à situação apresentada, bem como identificar necessidades de aprendizagem, construir novos significados e saberes, além de desenvolver competências específicas para o autoaprendizado. Estrategicamente, é a inserção, no decorrer de um curso, de um material social (textos, áudios, impressos, vídeos), cuja análise e discussão permitem contextualizar o conteúdo teórico. É muito útil no ensino de disciplinas básicas e pré-clínicas na área de saúde, conduzindo o aprendizado por meio de situações do cotidiano e da futura prática profissional. Os caminhos percorridos pelos alunos com a reflexão e a discussão dos casos motivadores permitem um contraste entre o senso comum e o senso universitário, que cria o movimento motivacional mediante o fluxo da prática e da realidade para o conteúdo teórico a ser trabalhado e pela oportunidade de gerar dilemas, opiniões, comparações e controvérsias no desenvolvimento do trabalho, com mediação do professor. Dessa forma, permite discutir e antecipar competências e habilidades futuras, além de proporcionar novas dimensões teóricas e práticas às vezes não previstas. É, portanto, uma oportunidade de o aluno criar a perspectiva da prática no momento em que tem contato teórico com o conteúdo da disciplina. É uma metodologia problematizadora mais versátil que o Problem Based Learning (PBL), pois pode ser inserida num curso tradicional (Lecture Based Teaching), não se tornando, assim, a única estratégia didática. Objetivamos, aqui, relatar nossa experiência na construção, aplicação e avaliação de dois casos motivadores voltados aos discentes do quarto ano do curso teórico de Oncologia da Faculdade de Medicina de Botucatu (Unesp). Os casos motivadores foram construídos com base em notícias divulgadas pela mídia e aplicados a uma turma de 27 discentes, divididos em dois grupos. A primeira sessão de discussão ocorreu na abertura do curso e a segunda sessão, no encerramento, quando os alunos apresentaram o resultado final do trabalho em forma de seminário. O fechamento dos casos motivadores ocorreu no final do curso, mediante aula dialogada sobre o tema "Prognóstico do Câncer", eixo comum dos dois casos motivadores. Tendo por base esta experiência, concluímos que o uso do Caso Motivador como prática pedagógica aproxima os alunos da realidade social e os leva a construir redes de conhecimentos, tornando-os sujeitos ativos do processo de aprendizagem, sem abrir mão da profundidade e da especificidade dos conhecimentos que um aluno de Medicina precisa desenvolver.
\end{abstract}




\section{KEY-WORDS}

- Motivation.

- Oncology.

- Active Learning

- Medical Education.

Recebido em: 16/5/2018

Aceito em: 20/6/2018
The motivational case, also called a problem situation or case study, is a student-focused learning method that involves problem solving, with the aim of assessing students' prior knowledge about a presented situation and identifying the learning needs, building new meaning and knowledge, and developing specific self-learning skills. Strategically, it involves the inclusion of social materials (text, audio, printed documents, videos) in the course for analysis and discussion, in order to provide a background context for the theoretical content being taught. It is a very useful tool for teaching basic and preclinical subjects in health care, leading the student through day-to-day situations that they will encounter in their future professional careers. The students' processes of reflection and discussion of the motivational cases enable a contrast to be made between common sense and academic judgment, which creates motivational movement through the flow of practice and reality to the theoretical content being taught, and the opportunity to generate dilemmas, opinions, comparisons and controversies during the work, mediated by the teacher. Thus, it allows future skills and abilities to be discussed and anticipated, as well as providing new theoretical and practical dimensions, sometimes unforeseen. It is, therefore, an opportunity for the student to create the perspective of practice, while the theoretical content of the subject is being learned. It is a more versatile investigative methodology than PBL (Problem Based Learning) as it can be inserted within a traditional course (Lecture Based Teaching) and is not necessarily the sole teaching strategy. Our aim in this work is to report our experience of the construction, implementation and assessment of two motivational cases designed for fourth year students of the theoretical Oncology course of Botucatu Medical School (Unesp). The motivational cases were built from news media and applied to a class of twenty-seven students, divided into two groups. The first discussion session took place at the start of the course and the second session took place at the end of the course, when the students presented their final work in the form of a seminar. The motivational cases were concluded at the end of the course, through a participatory class on "Cancer Prognosis", a theme that was common to the two motivational cases. Based on this experience, we conclude that the use of the motivational case as a pedagogical tool gives students a better understanding of the social reality, enabling them to build knowledge networks, and turning them into active subjects of the learning process, without sacrificing the depth and specificity that medical students need to develop.

\section{INTRODUÇÃO}

O ensino médico no Brasil vem se organizando, na maioria das vezes, em currículos tradicionais, com uma proposta de ensino-aprendizagem restrita à reprodução do conhecimento, em que o docente assume o papel de transmissor de conteúdo, ao passo que ao discente cabem a retenção e a repetição do mesmo ${ }^{1}$. Esta abordagem, predominante também na educação dos outros profissionais da área da saúde, baseia-se sobretudo em aulas expositivas (Lecture-Based Teaching ou LBT), procurando oferecer uma visão geral de determinado tema a muitos alunos. No entanto, a monotonia e a natureza passiva da transmissão de informação colocam em risco o processo de aprendizagem dos alunos, tornando-os receptores e meros espectadores frente a ele ${ }^{2}$. Uma ênfase excessiva no LBT nos primeiros anos dos cursos superiores pode levar a uma dissociação entre teoria e prática e retardar a compreensão de uma visão integral dos seres humanos, privilegiando os aspectos biomédicos e, desse modo, dificultando a construção de uma concepção ampliada do cuidado.

Na contraposição desta prática, que é reflexo de uma visão positivista da ciência moderna, experiências inovadoras no ensino superior fazem parte de um processo situado num contexto histórico e social que exige ruptura ${ }^{3}$. Conforme Mitre et al. ${ }^{1}$ :

No atual contexto social, no qual os meios de comunicação estão potencializados pelo avanço das novas tecnologias e pela percepção do mundo vivo como uma rede de relações 
dinâmicas e em constante transformação, tem-se discutido a necessidade de urgentes mudanças nas instituições de ensino superior, visando, entre outros aspectos, à reconstrução de seu papel social. (p. 2135)

Logo, é a própria dinâmica social que impõe a mudança na forma de ensinar-aprender dos novos cidadãos. Os currículos mais inovadores de educação médica buscam priorizar métodos de ensino e aprendizagem ativos e participativos ${ }^{4} \mathrm{e}$ vêm sendo construídos segundo práticas educacionais voltadas à educação problematizadora, que tem como pilar fundamental a participação crítico-reflexiva do aluno ${ }^{5}$. A educação problematizadora trabalha a construção de conhecimentos com base na vivência de experiências significativas ${ }^{3}$. Assim, as metodologias problematizadoras são propostas que trabalham com problemas para o desenvolvimento dos processos de ensinar e aprender ${ }^{6}$. Entre as propostas pedagógicas mais conhecidas que utilizam as estratégias problematizadoras estão o Problem-Based Learning (PBL) e a Metodologia da Problematização, que são distintas tanto na visão teórica como na prática.

No $P B L$, a organização e a prática curricular se fundamentam na construção de problemas a serem equacionados pelos estudantes. Isto implica modelações no espaço físico e de recursos humanos, envolvendo instalações das salas de aula, bibliotecas, laboratórios, distribuição das atividades, horários e capacitação de recursos humanos ${ }^{6}$. A decisão de adotar o $P B L$, portanto, é pedagógica, administrativa, econômica e política logo, ideológica. O problema é uma formulação com base na experiência dos professores e coerente com os objetivos educacionais a serem atingidos, como a ponta do fio do novelo de lã, o condutor de um caminho a ser trilhado no processo de aprendizagem.

A Metodologia da Problematização (MP) é (de)composta de cinco etapas, conforme o Método do Arco de Charles Maguerez ${ }^{7}$, que são desencadeadas a partir de uma realidade ou de um recorte da realidade: observação da realidade; pontos-chave; teorização; hipótese de solução; e aplicação à realidade (prática). A teoria é reconstruída a partir da prática, com o objetivo de modificar a realidade encontrada e o problema é a oportunidade, propositadamente inserida para uma visão crítica da realidade. A problematização está associada à abordagem de um assunto já vivenciado para que seja de fato útil do ponto de vista pedagógico.

É importante ressaltar que, como alternativas ao PBL e à $\mathrm{MP}$, outros métodos de ensino podem apresentar enfoques problematizadores no processo de ensino e aprendizagem. Entre estas estratégias estão a Discussão de Casos Clínicos,
Aprendizagem por Projetos, Aprendizagem por Pesquisa e os Casos Motivadores.

\section{CASO CLÍNICO E CASO MOTIVADOR: MÉTODOS DE ENSINO E RESULTADOS}

Os Casos Clínicos são situações reais ou fictícias, com dados resumidos e intencionalidade cognitiva, cujo objetivo é introduzir ou ilustrar determinado conhecimento. Porém, por conta de sua natureza teórica, não permitem a experiência real, sendo apenas uma proposta artificial, parcial, sistematizada e teórica da prática profissional, às vezes apresentada com tom caricatural. A inserção de caso clínico nas disciplinas do ciclo básico sem a devida contextualização e sem a devida bagagem da vivência prática pode desestimular ou ser pouco esclarecedora, distorcendo, inclusive, a realidade profissional. Por outro lado, a apresentação e a discussão de casos clínicos em sala de aula como forma de estímulo à reflexão são imprescindíveis quando o aluno já está inserido na prática profissional - como no internato, no caso dos cursos de Medicina, ou na vivência de enfermarias, nos cursos de Semiologia -, pois o conhecimento da realidade prática, mesmo inicial, permite uma postura crítica do aluno perante a situação apresentada, sendo verdadeiramente problematizadora.

O Caso Motivador é uma metodologia ativa de ensino-aprendizagem, também denominada situação-problema ou Case Study Methodology ${ }^{8}$. Embora tenha sido elaborada para utilização no ensino em áreas como Administração e Economia, a metodologia vem sendo usada na área da saúde pela possibilidade de gerar compreensões de profundidade, multifacetadas, numa contextualização aproximada da realidade ${ }^{9}$. São relatos clínicos ou situações-problema apresentados e/ou construídos com propósitos educacionais específicos, a fim de estimular o estudante a desenvolver conhecimentos, habilidades e atitudes considerados primordiais ao equacionamento do caso e ao aprendizado naquele momento, motivando-os para esta etapa da formação. Na proposição do Caso Motivador, a solução apresentada é menos uma ilustração da teoria, mas uma proposta desafiadora, uma situação que permita ao aluno se inserir sem demora no cenário da prática, usando o conteúdo teórico como ferramenta para desvendar o problema. No Caso Motivador, de modo distinto da utilização do Caso Clínico, a resolução do problema não está apenas na teoria ou no conteúdo da aula. Sozinho ou em grupo, o aluno deve buscar esse conteúdo, construindo e somando de modo ativo a própria teoria. O Caso Motivador tem como componente atrativo o fato de poder ser extraído do senso comum, da mídia, de acesso fácil a qualquer pessoa no mundo atual, sem necessidade de conter uma visão absoluta ou um tema 
completo. Notícias de jornal ou telejornal, trechos de vídeos, artigos de revistas, publicidade, fotos, imagens, poesias, frases são exemplos de material apresentados em separado ou em conjunto como Caso Motivador.

A metodologia do Caso Motivador, por promover a mobilização do senso comum, permite conhecer e desafiar os saberes prévios do grupo de alunos frente à situação apresentada, bem como identificar necessidades de aprendizagem, construir novos significados e saberes, além de desenvolver competências específicas para o estudo independente ${ }^{10}$. Diferencia-se da discussão de Caso Clínico pelo fato de a situação apresentada desafiar o conhecimento do aluno a partir do que ele já traz de conhecimento de vida. Mesmo desconhecendo o conteúdo teórico, o aluno compreende a situação apresentada e assume a possibilidade de resolução. Após a apresentação da proposta, segue-se a discussão em grupo, que apresenta as várias perspectivas e opiniões envolvidas, muitas delas contraditórias ou parciais, conscientizando o aluno de que seu conhecimento atual é insuficiente para uma compreensão resolutiva ou uniformizadora. Segue-se a busca ativa pelo conhecimento e conteúdo teórico, sempre sob a orientação do professor, mediante o planejamento e a execução de uma estratégia pelo grupo, o que gera novas discussões e ampliação da perspectiva do problema, buscando sínteses conciliatórias.

Os objetivos pedagógicos da Discussão de Caso Clínico e do Caso Motivador são distintos (Quadro). O Caso Clínico é ilustrador da teoria, isto é, insere a prática na teoria, enquanto a proposta do Caso Motivador insere a teoria na prática. Enquanto o Caso Clínico extrai os elementos da prática e os apresenta de forma fechada (como uma colagem), o Caso Motivador familiariza o conhecimento, isto é, amplia a experiência já vivida e cria necessidades cognitivas. O Caso Clínico é extraído da clínica ou da idealização da teoria, enquanto o Caso Motivador faz parte do senso comum, tem caráter de pertencimento. O Caso Clínico restringe, o Caso Motivador amplia. A familiaridade da situação apresentada é o guia do Caso Motivador, ela é a ponte entre aquilo que já se sabe e o que se vai aprender. Teorizando sob o ponto de vista da neurociência, seria a criação de novas vias neurais a partir das já existentes. O senso comum é o elemento facilitador do aprendizado, estimulado pela discussão em grupo.

Outra característica do Caso Motivador é o fato de se incluir numa estratégia que exige resolução coletiva. A estratégia se baseia na formação dos grupos, seguida da apresentação do tema, discussão e criação de propostas para a abordagem mais aprofundada do tema, de forma semelhante à Metodologia da Problematização. Em seguida, os alunos irão buscar novas informações, que podem ser propostas pelo professor (um ou vários textos científicos ou trechos, em geral), etapa seguida de novas discussões em grupo, culminando numa síntese em grupo que será apresentada em sala de aula, na presença de outros grupos.

\begin{tabular}{|c|c|c|}
\hline \multicolumn{3}{|c|}{$\begin{array}{c}\text { QUADRo } \\
\text { Diferenças na construção e objetivos entre } \\
\text { Caso Motivador e Caso Clínico }\end{array}$} \\
\hline Itens de Comparação & Caso Clínico & Caso Motivador \\
\hline Natureza & Real ou ficcional & Real \\
\hline Com relação à teoria & Reforça & Amplia \\
\hline Elaboração & $\begin{array}{l}\text { Formulado pelo } \\
\text { professor }\end{array}$ & $\begin{array}{l}\text { Retirado da } \\
\text { realidade social }\end{array}$ \\
\hline Objetivo & $\begin{array}{l}\text { Diagnóstico } \\
\text { e conduta }\end{array}$ & $\begin{array}{l}\text { Integração de } \\
\text { conhecimentos }\end{array}$ \\
\hline Ideal para inserção & No internato & No ciclo básico \\
\hline $\begin{array}{l}\text { Integração do conteúdo } \\
\text { teórico }\end{array}$ & $\begin{array}{c}\text { Com o raciocínio } \\
\text { clínico }\end{array}$ & Com a realidade \\
\hline Relação com a teoria & Ilustração & Confrontação \\
\hline $\begin{array}{l}\text { Proximidade com o } \\
\text { senso comum }\end{array}$ & Baixa & Alta \\
\hline Personagens utilizados & Estereótipos & Com vivência real \\
\hline Centrado & No professor & $\begin{array}{l}\text { No grupo de } \\
\text { alunos }\end{array}$ \\
\hline
\end{tabular}

Fonte: Dados da pesquisa

O Caso Motivador pode ser explorado de diversas formas, seja numa única aula ou aplicado de forma longitudinal durante um curso teórico. Neste sentido, os alunos utilizarão o Caso Motivador como elemento alinhador de vários conteúdos teóricos apresentados no curso, costurando os assuntos e tendo uma visão de conjunto. Pode ser utilizado como um único tema para vários grupos, quando a escolha de um tema amplo permite uma diversificação interessante para o conteúdo teórico, criando discussões e perspectivas diversas. Uma alternativa é indicar um tema para cada grupo de alunos, com a apresentação das diversas sínteses no final do curso. O papel do professor não se restringe à criação e proposta do tema. Além de explicitar a estratégia e sugerir a criação de lideranças (um coordenador e um secretário, por exemplo), o professor deve acompanhar tanto as discussões quanto o desempenho de trabalho dos grupos. E, talvez o mais essencial, deve garantir momentos durante a aula ou o curso para que os grupos possam desenvolver o trabalho, reunir-se e finalizar as apresentações.

A seguir, a título de exemplificação, apresentamos duas propostas diversas que permitem diferenciar a Discussão de Caso Clínico e Caso Motivador numa aula sobre tuberculose. Em vez de descrever um homem de 20 anos de idade, presidiário, com tosse há 30 dias, como seria decerto uma proposta 
de ilustração para Discussão de Caso Clínico, apresenta-se, como Caso Motivador, uma reportagem verídica do jogador de futebol da seleção brasileira Thiago Silva, que concedeu entrevista ao programa Globo Esporte em junho de 2013, onde ele conta sua experiência com a tuberculose durante sua passagem profissional na Rússia ${ }^{11}$. Enquanto o presidiário tipifica o doente, criando um estereótipo do paciente com tuberculose, inclusive possibilitando reforçar preconceitos, o aluno, ao tomar conhecimento de que um atleta de alto nível como Thiago Silva também teve tuberculose amplia sua visão a respeito do assunto teórico e, sobretudo, permite um exercício de identificação, isto é, subjetiva a doença em si mesma - em outros termos, o aluno entende que ele mesmo poderia ser alguém com tuberculose.

Pela sua natureza mobilizadora, a problematização, a partir da aplicação dos Casos Motivadores, permite ampliar o assunto teórico para novas dimensões além da visão biomédica, envolvendo as áreas de Comunicação, Psicologia, Sociologia, e favorecendo a empatia quando aborda a experiência dos pacientes. Desse modo, tem a potencialidade de integrar e comungar diversos conteúdos e temas paralelos em uma síntese conciliatória $^{12}$. Na dimensão problematizadora do processo ensino-aprendizagem, o Caso Motivador tem o potencial de motivar para o aprendizado mediante a exposição do aluno a uma situação apresentada, estimulando-o a compreender a relação entre conteúdo teórico e realidade. A inserção dos Casos Motivadores nas atividades de ensino é uma estratégia problematizadora de grupos eficiente, a ser aplicada em cursos das áreas da saúde cujos conteúdos teóricos são ensinados com distância temporal e física da vivência prática.

Abordaremos neste artigo nossa experiência na aplicação de Caso Motivador aos discentes do quarto ano médico da Faculdade de Medicina de Botucatu da Universidade Estadual de São Paulo (FMB-Unesp) no curso de Oncologia Clínica, ministrado a turmas de 30 alunos, com carga horária total de 52 horas, dividida em 13 períodos de quatro horas, aplicadas em pouco mais de uma semana corrida. Este curso faz parte da grade curricular obrigatória e conta com a participação das disciplinas de Oncologia Clínica, Radioterapia, Diagnóstico por Imagem, Medicina Nuclear, Ginecologia, Hematologia, Geriatria e Patologia Clínica. Até a implantação da metodologia dos Casos Motivadores, o curso de Oncologia se baseava em aulas expositivas, não articuladas uma às outras, com avaliações isoladas por disciplinas ou professores. A aplicação dessa metodologia teve por objetivo promover uma articulação entre os temas do curso, despertando nos alunos o interesse pelo conteúdo trabalhado, levando-os a identificar necessidades de aprendizagem, partindo para a busca de in- formações, construindo novos significados e desenvolvendo competências. Esta metodologia foi aplicada de modo longitudinal, com as atividades iniciadas no primeiro dia do curso, tendo se encerrado com a apresentação dos resultados pelos alunos no último dia do curso. Entre as alterações necessárias à implantação do método, após a aprovação de todos os professores participantes, as aulas foram reprogramadas, com a condensação de alguns temas para oferecer novos espaços à estratégia.

\section{APLICAÇÃO DA METODOLOGIA DOS CASOS MOTIVADORES NO CURSO DE ONCOLOGIA}

Iniciamos a construção do Caso Motivador com o delineamento dos objetivos de aprendizagem a serem alcançados pelos alunos. Além do estudo dos diferentes tipos de câncer e sua patogênese, o curso de Oncologia Clínica pretendeu que os alunos compreendessem a importância da relação entre diagnóstico, estadiamento, tratamento e prognóstico, e a grande relevância do registro adequado no prontuário no acompanhamento clínico dos pacientes, pois a qualidade dos registros médicos pode interferir no resultado do tratamento dos pacientes. Os professores perceberam que os dois temas tinham em comum a questão do prognóstico como elemento teórico conciliador. O prognóstico é, com certeza, um assunto com que os alunos dos anos iniciais não se identificam de imediato, pois se preocupam, em geral, com o diagnóstico e tratamento. Por conseguinte, poderíamos criar uma necessidade de entendimento e apropriação do conteúdo "prognóstico" como uma finalidade adicional do curso teórico. Com estes objetivos, partimos para a construção dos casos.

Optamos por montar os Casos Motivadores com base em notícias jornalísticas, partindo do senso comum, abordando tópicos relevantes para a área e para o momento de aprendizagem do aluno. Procuramos notícias com uma ou mais questões a serem confrontadas e selecionadas por meio de debate, levando a controvérsias e proporcionando diferentes interpretações, decisões e planos de ação. Construímos dois Casos Motivadores, que serão apresentados a seguir. Ambos têm uma estrutura curta, constituída por informações em quantidade apropriada e bem relatadas, a fim de proporcionar aos alunos uma viagem de descoberta, aproximando-os da realidade e permitindo-lhes estender as lições e os conceitos subjacentes do caso para outras situações.

A discussão de cada Caso Motivador foi realizada em dois grupos de 15 alunos, um caso distinto para cada grupo. O grupo escolheu um coordenador e um secretário entre seus participantes. O aluno coordenador fez a leitura do texto e organizou a discussão do caso. $\mathrm{O}$ aluno secretário cuidou para que 
todos os participantes contribuíssem na discussão. A primeira sessão de discussão aconteceu na abertura do curso, durante um período de duas horas, quando, após a apresentação e explicitação da proposta, houve a formação dos dois grupos.

Em seguida, cada grupo recebeu a documentação, seguida da leitura do Caso Motivador e do início do debate a partir de conhecimentos prévios, com levantamento de dúvidas, definição de objetivos e organização da estratégia para a busca de novas informações. O papel do professor, neste primeiro encontro, foi cuidar para que os alunos não se perdessem na discussão e não se afastassem dos objetivos de aprendizagem delineados na construção do caso. No final desta atividade, professor e alunos fizeram a síntese das conclusões e estabeleceram as metas e o cronograma de trabalho dos dias seguintes, individual e coletivamente.

Os alunos buscaram as informações necessárias à conclusão do trabalho durante as aulas teóricas e/ou práticas ministradas durante o curso ou por meio de estudo em livros e discussão com professores de outras disciplinas ou profissionais da saúde de diferentes áreas. Com o rearranjo das aulas, houve a criação de um período livre, de quatro horas, durante a semana para possibilitar que os grupos se reunissem a fim de discutir novos conhecimentos e sínteses, sendo destinado o último dia do curso à apresentação dos resultados pelos alunos e à avaliação final do curso. Entre o primeiro dia do curso e a apresentação dos resultados, transcorreram seis dias úteis.

Os grupos apresentaram os resultados do trabalho em forma de seminário no último dia do curso. Foi neste momento que eles relataram o progresso alcançado após o período de estudos, reflexões e discussões, individual e coletivo, com o aprofundamento dos questionamentos e do conhecimento, agora como sujeitos ativos do processo de ensino-aprendizagem. Dois professores do curso participaram deste encontro com a finalidade de avaliar os seminários e realizar o fechamento do tema abordado, guiados pelos questionamentos e sínteses apresentados pelo grupo durante esta discussão final. Foi utilizado um período de quatro horas, no qual os dois grupos apresentaram os resultados do trabalho tendo por base as questões levantadas no primeiro encontro, com o objetivo de compartilhar os trabalhos realizados e, junto com os professores, esclarecer as dúvidas e novas questões.

\section{Caso Motivador 1}

Um político (Político 1) anunciou em entrevista coletiva que está em tratamento quimioterápico contra um câncer em estágio inicial, descoberto após retirar um tumor de 2,5 cm em sua axila direita durante uma avaliação médica de rotina. Segundo os médicos que cuidam dele, o tumor é um linfoma de grandes células, câncer do sistema linfático, no estágio IA. O político deve passar por quatro meses de quimioterapia, utilizando drogas tradicionais e uma droga-alvo específica, o rituximab.

Um segundo político (Político 2), tabagista de longa data, do mesmo partido que o Político 1, foi diagnosticado com câncer na laringe, do tipo carcinoma espinocelular, supraglótico, com $3 \mathrm{~cm}$ de diâmetro, T1N0M0. A doença foi descoberta por meio de uma série de exames feitos a pedido do seu médico, que desconfiou de uma rouquidão persistente relatada pelo paciente durante a sua festa de aniversário. O tratamento já teve início com sessões de quimioterapia, e os médicos só cogitam cirurgia caso a quimioterapia e a radioterapia não surtam efeito. Segundo a equipe médica, o tumor pode afetar a voz do paciente, mas isso não deve interferir em seus futuros planos politicos.

Com base nos relatos descritos acima e nos conhecimentos atuais de Oncologia sobre tratamento e prognóstico destas doenças, qual dos dois políticos deveria ser escolhido como candidato daquele partido à eleição para presidente da República, tendo como base aquele com melhor prognóstico e maior chance de concluir seu mandato com saúde? Justifique.

Logo na leitura do Caso Motivador 1, os alunos ligaram a situação hipotética a fatos com base na história política brasileira da época. Procuraram integrar novos dados disponíveis na mídia, como reportagens de jornais e telejornais. Durante a busca de informações para responder às questões lançadas pelo caso, os alunos planejaram e entraram em contato com professores das disciplinas de Radioterapia, Patologia, Hematologia e Cirurgia de Cabeça e Pescoço. Optaram pela divisão em dois subgrupos, um para cada político, para a preparação e apresentação do seminário. Esta decisão criou duas visões diferentes, sendo que cada grupo procurou defender seu candidato como o mais presidenciável para a hipotética decisão partidária, sempre de acordo com a melhor resposta terapêutica de longo prazo. A estratégia coletiva do grupo, porém, procurou estabelecer para cada político uma associação entre diagnóstico, estadiamento, tratamento e prognóstico em Oncologia, conforme havíamos idealizado durante o planejamento e criação dos Casos Motivadores.

O subgrupo que estudou o Político 1 destacou a utilização - um tanto recente e inovadora no arsenal terapêutico dos linfomas - do anticorpo monoclonal anti-CD20, com melhoria importante do prognóstico quando utilizado em conjunto com a quimioterapia tradicional. Pelo fato de o Político 1 ter sido diagnosticado com o estádio inicial da doença e ter sido utilizada esta nova proposta terapêtica, o subgrupo concluiu que a chance de cura era alta e não impediria uma candidatura à presidência.

O subgrupo que estudou o caso do Político 2, além dos aspectos teóricos da doença, associou fatores de risco (conhe- 
cidos) presentes, como o tabagismo, e especulativos, como o etilismo. Ressaltou a questão da escolha da estratégia terapêutica do caso, isto é, a preservação da laringe (não cirúrgica) e a utilização de quimioterapia e radioterapia, pelo fato de a voz ser um instrumento importante para os políticos, tendo em vista o diagnóstico precoce do tumor naquele paciente. Levantou a hipótese de que a estratégia terapêutica envolveu uma decisão conjunta do paciente e dos médicos, com vistas a uma possível candidatura eleitoral. Os alunos deste subgrupo concluíram que o Paciente 2 teria chances de seguir na carreira política sem recaída da doença por ter desenvolvido um tumor com potencial de cura e tratamento adequado.

O debate que se seguiu mostrou a diversidade de opiniões entre os subgrupos, sendo que o segundo subgrupo concluiu que o político portador do linfoma teria melhor prognóstico porque o linfoma não Hodgkin de grandes células em estádio inicial tem melhor prognóstico de cura em comparação ao câncer de laringe sem o tratamento curativo ideal, que seria a cirurgia de retirada do tumor e/ou a laringectomia. Além disso, concluíram que as chances de recaída do tumor de laringe do segundo político eram maiores, por sua provável exposição continuada aos fatores de risco, como o tabagismo. Porém, o subgrupo do Político 2 rebateu a argumentação utilizando o fato de que as informações presentes na mídia não eram oficiais e que as decisões médicas levaram em conta o estádio precoce no diagnóstico. A conclusão de alunos e professores foi que os dois candidatos tinham recebido os melhores cuidados médicos disponíveis e estavam com suas doenças sob controle, com perspectiva de cura alta e possibilidade de disputarem a vaga do partido para a eleição presidencial, e que esta escolha seria muito mais política que oncológica.

\section{Caso Motivador 2}

Embora tenha sido particular e inusitada, a cerimônia de casamento entre Romeu e Julieta acabou ganhando as redes sociais e causou grande repercussão. O cerimonial seguiu a tradição de um casamento comum, salvo por um detalhe: ele foi realizado em uma das alas de um hospital. A união foi o último desejo do noivo, que morreu três dias depois, vítima de câncer em múltiplos órgãos. Romeu descobriu a doença havia quatro anos e, após a primeira cirurgia para tentar conter o avanço do tumor, pediu Julieta em casamento. Entretanto, a doença continuou evoluindo, e o plano de casamento foi sendo adiado até que, no dia 30 de junho, a união aconteceu, com Julieta entrando com vestido de noiva, música e muita emoção. No corredor de uma das alas do hospital, que foi fechada para dar privacidade à cerimônia, a noiva foi levada até o altar improvisado onde Romeu a esperava. Ele estava internado havia três semanas e sabia que teria só mais alguns dias de vida. Resolveu, então, realizar o sonho de se casar com
Julieta, com quem namorava havia cinco anos. Ele passou por vários tratamentos e internações desde que a doença foi descoberta, sem êxito. Em junho, foi alertado pelos médicos de que precisaria passar por uma nova cirurgia, mas não aceitou. E quis, antes de morrer, realizar o sonho de se casar. Para se casarem, os noivos tiveram a ajuda da equipe médica, enfermagem e funcionários, que organizaram e pagaram a festa que ficou pronta em dois dias, com direito a música, bolo e salgadinhos, além da presença de um pastor, que oficializou a união. Romeu morreu três dias depois da cerimônia. Para Julieta, o que fica são as lembranças dos bons momentos de anos de namoro e dos dias de casamento. Diz que nunca o viu reclamando e era divertido, extrovertido, animado, sempre brincalhão e tinha muita fé em Deus. "É isso que eu vou guardar do meu noivo", disse Julieta.

Os profissionais da saúde do hospital foram além do cuidado técnico-científico e se preocuparam não só com a dor física do paciente, mas com seu sofrimento psíquico, social e espiritual. Porém, este casamento tardio pode ter ocorrido pela falta de percepção do paciente sobre a terminalidade de sua doença. Analise os motivos que levaram Romeu a não se casar antes:

1. Sob o ponto de vista do paciente e de sua noiva;

2. Acerca da atuação da equipe de saúde no acompanhamento ambulatorial.

A proposta do Caso Motivador 2 foi analisar os motivos que levaram Romeu a protelar seu casamento tanto pela perspectiva do paciente como de sua noiva e considerando a atuação da equipe de saúde no acompanhamento ambulatorial deste paciente. Devido ao grande apelo emocional, tanto pela juventude dos noivos como pela situação dramática abordada na mídia, pudemos observar durante a leitura da documentação do caso que dois alunos se emocionaram muito e choraram, sendo consolados pelos colegas. O grupo sentiu necessidade de discutir o caso com professores das disciplinas de Psicologia, Cuidados Paliativos e Patologia, visitaram o serviço ambulatorial de Oncologia para conhecer seu funcionamento e fizeram entrevistas com a equipe de profissionais da enfermaria onde o paciente esteve internado, inclusive com a residente de Clínica Médica, que organizou o casamento. Os alunos solicitaram acesso aos registros clínicos do paciente e se surpreenderam com o fato de que a comunicação da falta de um prognóstico de cura ocorreu apenas poucos meses antes da morte do paciente, embora este fato fosse conhecido pela equipe médica desde os primeiros meses do início do tratamento. Segundo os mesmos registros, devido à natureza do tumor e da não resposta quimioterápica e radioterápica, o paciente foi encaminhado à Psicologia. Outro aspecto relevante para os alunos foi a ausência de qualquer registro da cerimônia de casamento realizada. 
Na apresentação do Caso Motivador 2, além das questões biomédicas, os alunos apresentaram um vídeo de uma reportagem sobre o casamento, obtido na internet, e ressaltaram a empatia e compaixão demonstradas pela equipe da enfermaria, que se empenhou para conseguir realizar a cerimônia. Outro ponto reforçado pelos alunos foi a necessidade de se comunicarem de forma efetiva com os pacientes, escutando suas expectativas, e a necessidade de rigor no registro de dados nos prontuários dos pacientes.

\section{Fechamento dos casos motivadores}

Para o fechamento dos casos motivadores, nós, professores, preparamos uma discussão acerca de Prognóstico em Oncologia, eixo comum dos dois casos motivadores. Pretendíamos, num primeiro momento, demonstrar como médico e pacientes, durante o encontro clínico, têm visões e modelos explicativos diferentes, isto é, quais aspectos semióticos estão envolvidos nesta relação. A perspectiva do paciente é a forma como ele experimenta todos os aspectos da doença, inclusive seus efeitos sobre os relacionamentos e função social. Em inglês, esta perspectiva é expressa como illness. A perspectiva do médico é biológica, e é expressa em inglês como disease. Esta indesejada visão particular da medicina, em detrimento da vivência do paciente, se reflete logo nas primeiras aulas de Semiologia, onde os alunos são instruídos pelos professores a limpar a história, ou seja, a ignorar a illness, a perspectiva do paciente, para valorizar a disease, o contexto biológico da doença.

Outro ponto foi a apresentação do resumo de dois artigos científicos. O primeiro, de $2012^{13}$, verificou que até $81 \%$ dos pacientes com câncer avançado desconheciam o caráter não curativo do tratamento quimioterápico a que estavam sendo submetidos. $\mathrm{O}$ estudo sugere que este desconhecimento compromete a capacidade do paciente de tomar decisões importantes. Os autores acreditam que os médicos omitem informações porque isto poderia diminuir a satisfação do paciente em relação a eles. Um segundo estudo, publicado em 2001, demonstra que pacientes atendidos por médicos de família do Canadá são interrompidos, em média, 11 segundos após o início de sua fala, o que mostra o quanto os médicos não escutam de fato seus pacientes ${ }^{14}$. Estes estudos alertam sobre as dificuldades de comunicação entre médicos e pacientes, de ouvir os pacientes, de conhecer suas expectativas e, no caso da Oncologia, de lidar com situações semelhantes, como pode ser verificado no Caso Motivador 2, em que o paciente decidiu se casar dias antes de sua morte por talvez desconhecer seu prognóstico de forma realística.

A avaliação desta estratégia metodológica comporta uma diversidade de ferramentas e pode ser realizada em mais de um momento. Na fase de busca de informação, os professores avaliaram os grupos de alunos de acordo com a participação, capacidade de escuta, conhecimentos prévios, iniciativa e disponibilidade para o trabalho em grupo. Na fase final, os alunos foram avaliados pelos conhecimentos adquiridos durante este processo, mediante apresentação de seminários que abordaram conceitos, epidemiologia, fisiopatologia, diagnóstico, estadiamento, tratamento e prognóstico. Quanto à avaliação do aluno, foram atribuídas notas ao desempenho do grupo, levando-se em conta a participação nas discussões, na estratégia adotada e no desempenho na exposição final. Não houve avaliação individual nesta primeira experiência. Esta nota se somou à de outras atividades em sala de aula das disciplinas participantes, porém teve peso maior na nota final.

Como estratégia de ensino, a metodologia foi avaliada por questionário que mediu o interesse provocado nos alunos no tocante ao tema, se estes alunos ficaram motivados e/ou mais questionadores durante o curso e se os objetivos delineados foram alcançados. Caberia ainda, neste processo avaliativo, a autoavaliação, na qual cada aluno avalia sua participação, sua contribuição para o grupo e as atividades desempenhadas, mas, devido ao pioneirismo da aplicação da proposta, não foi utilizada, inclusive pelo pouco tempo disponível para as atividades do último dia do curso. Para esta avaliação da estratégia dos Casos Motivadores, convidamos 27 alunos. Destes, 25 responderam ao questionário (Tabela), 23 alunos consideraram o tema dos Casos Motivadores relevante, 01 aluno achou o assunto repetitivo, e outro o considerou inadequado. $\mathrm{O}$ tempo de 10 horas/aula destinado a esta metodologia, 23 alunos o consideraram suficiente, e dois alunos o consideraram excessivo. A respeito da didática, 22 alunos consideraram a atividade adequada, e três a consideraram inadequada.

\begin{tabular}{|c|c|c|}
\hline \multicolumn{3}{|c|}{$\begin{array}{l}\text { ТАвELA } \\
\text { da avaliação dos alunos sobre o } \\
\text { os Motivadores como estratégia } \\
\text { ino no curso de Oncologia }\end{array}$} \\
\hline & $\mathrm{N}=25$ & $\%$ \\
\hline \multicolumn{3}{|l|}{ Tema } \\
\hline Relevante & 23 & 92 \\
\hline Repetitivo & 1 & 4 \\
\hline Inadequado & 1 & 4 \\
\hline \multicolumn{3}{|c|}{ Duração total dos encontros (10 horas) } \\
\hline Insuficiente & - & - \\
\hline Suficiente & 23 & 92 \\
\hline Excessiva & 2 & 8 \\
\hline \multicolumn{3}{|l|}{ Didática } \\
\hline Adequada & 22 & 88 \\
\hline Inadequada & 3 & 12 \\
\hline
\end{tabular}


Os alunos comentaram os pontos fortes e fracos do Caso Motivador, os quais destacamos:

$$
\begin{aligned}
& \text { [...] poderia delinear e delimitar melhor quais seriam os ob- } \\
& \text { jetivos. }
\end{aligned}
$$

A estratégia do Caso Motivador foi bem inovadora e muito inteligente, nos engajou na pesquisa de temas não abordados durante a graduação (como prognósticos, questões afetivas e políticas).

Foi uma ótima oportunidade para lidar com aspectos que não se limitam ao biológico.

Foi interessante discutir com colegas sobre os diversos aspectos do paciente com câncer e conhecer a diversidade dos cuidados paliativos.

Bem orientado e bom para ter uma visão mais ampla da Oncologia.

O melhor foi a aula de fechamento, concluindo a importância da discussão desses casos.

\section{CONSIDERAÇÕES FINAIS}

O Caso Motivador foi uma ferramenta didática utilizada para iniciar e concluir o curso de Oncologia Clínica para alunos do quarto ano do curso de Medicina da FMB-Unesp. Antes, o curso era teórico, com predomínio de aulas expositivas, sem a participação ativa dos alunos, com aulas sem articulação quanto ao conteúdo e com avaliações isoladas pelas diversas disciplinas participantes. A partir da aplicação do Caso Motivador de modo longitudinal, os alunos tiveram a oportunidade de debater e sintetizar em grupos os diversos assuntos lecionados sob um eixo norteador, no caso, o Prognóstico na Oncologia.

A opção pelo tema prognóstico teve como objetivo criar a possibilidade de explorar e discutir um aspecto que, de forma geral, os cursos médicos com foco biológico não priorizam, ressaltando mais as questões fisiopatológicas e terapêuticas. Por outro lado, sem dúvida, o prognóstico do câncer é a questão mais importante para os pacientes e a população em geral quando são diagnosticados com esta doença. Assim, a abordagem do tema prognóstico na metodologia dos Casos Motivadores, com a apresentação de casos e situações reais, extraídos do cotidiano e da mídia, resulta em reflexão e postura ativa dos alunos acerca do assunto tratado.

A partir desta experiência, concluímos que o uso do Caso Motivador como prática pedagógica aproxima os alunos da realidade social, leva-os a construir redes de conhecimentos, tornando-os sujeitos ativos do processo de aprendizagem, sem abrir mão da profundidade e da especificidade dos conhecimentos que um aluno de Medicina precisa desenvolver. A passagem da consciência ingênua para a consciência crítica requer a curiosidade criativa, indagadora e sempre insatisfeita de um sujeito ativo e motivado. A motivação se produz no cruzamento dos projetos pessoais com as condições socioeducativas e favorece a organização dos estudos, acompanhamento das mudanças, aprendizagem e crescimento pessoal e profissional. Nesta perspectiva, o Caso Motivador, além da questão motivacional, permite que o aluno crie formas de contextualizar o conhecimento que está sendo abordado e, em especial, encontrar, dentro de si mesmo, os questionamentos necessários a uma compreensão com sentido.

O fato de a Metodologia do Caso Motivador envolver o trabalho em grupo gera reflexões, problematização, escuta do outro, devido à necessidade de consensos e decisões coletivas, além das demandas científicas e de outras perspectivas do cuidado em saúde. Além disso, contribui para criar e realçar laços afetivos e para a aquisição de ferramentas de socialização, preparando os alunos para um trabalho profissional coletivo.

Outro aspecto relevante da aplicação da Metodologia do Caso Motivador é o fato de que sua implantação pode ocorrer numa estrutura curricular tradicional, não demandando alterações institucionais pedagógicas, como no caso do $P B L$, embora exija planejamento cuidadoso e rearranjo das atividades em sala de aula. É fundamental que o professor acompanhe todas as etapas, incluindo a explicitação da estratégia, criação e organização dos grupos e a elaboração das estratégias para estudo e apresentação dos resultados. Também é necessário que o cronograma preveja a presença de espaços curriculares para o encontro dos alunos, para discussões e conclusões. Observamos que os grupos tendem a se concentrar ou nos aspectos biomédicos ou nos sociais e psicológicos, evidenciando a visão (prejudicial) de dualidade em sua formação profissional. É importante que o professor integre estas duas abordagens de forma harmônica e holística. Com certeza, é uma alternativa mais desafiadora que a Discussão de Casos Clínicos, em especial para alunos que não estão em contato direto com a prática profissional.

As abordagens pedagógicas problematizadoras favorecem a formação de profissionais com competências éticas, políticas e técnicas, dotados de conhecimento, raciocínio, crítica, responsabilidade e sensibilidade para as questões da vida e da sociedade, capacitando-os para intervirem em contextos de incertezas e complexidades. Deste modo, casos motivadores são parte da estratégia problematizadora no ensino superior 
da área da saúde. Como esta foi a primeira experiência dos autores com Caso Motivador, não houve o planejamento de uma avaliação com outras ferramentas, como avaliação entre grupos, entre pares e autoavaliação. Estas estratégias, conectadas, enriquecerão a avaliação e a própria dinâmica da aplicação do método, apontando novas propostas de pesquisa.

\section{REFERÊNCIAS}

1. Mitre SM et al. Metodologias ativas de ensino-aprendizagem na formação profissional em saúde: debates atuais. Ciênc. Saúde Coletiva 2008;13(2):2133-2144.

2. Latif R. Impacto of case-based lectures on students' performance in vascular physiology module. Advances in Physiology Education 2014;38:268-272.

3. Cyrino E,Toralles-Pereira L. Trabalhando com estratégias de ensino-aprendizado por descoberta na área da saúde: a problematização e a aprendizagem baseada em problemas. Caderno de Saúde Pública 2004;20(3):780-788.

4. Souza CS, Iglesias AG, Pazin-Filho A. Estratégias inovadoras para métodos de ensino tradicionais - aspectos gerais. Medicina 2014;47(3):284-292.

5. Batista NA. Desenvolvimento docente na área da saúde: uma análise. Trabalho, Educação e Saúde 2005;3(2):283294.

6. Berbel NAN. A problematização e a aprendizagem baseada em problemas: diferentes termos ou diferentes caminhos? Interface Comunicação, Saúde e Educação 1998; 2:139-54.

7. Bordenave JD, Pereira AMP. Estratégias de Ensino-Aprendizagem. 12ª Edição. Petrópolis: Editora Vozes, 1991.

8. Tellis WM. Application of a Case Study Methodology.The Qualitative Report1997; 3(3):1-19.

9. Crowe S, Cresswell K, Robertson A, Huby G, Avery A, Sheikh A. The case study approach. BMC Medical Research Methodology 2011; 11:100-109.

10. Batista NA, Vilela RQB, Batista, SHSS. Metodologias ativas de ensino aprendizagem (Maea): potências para aprender e ensinar em medicina. In: Educação Médica no Brasil. São Paulo: Cortez, 2017. p. 219-234.

11. Asmar T, Rodrigues J. Origens: Thiago Silva abre o jogo e se emociona ao lembrar das dificuldades. Grupo Globo [on-line]. 2013.[capturado 21fev.2018]. Disponível em http:/ / globoesporte.globo.com/programas/esporte-espetacular/noticia/2013/06/origens-thiago-silva-abre-o-jogo-e-se-emociona-ao-lembrar-das-dificuldades.html
12. Pereira OP, Almeida, TMC. A formação médica segundo uma pedagogia de resistência. Interface - Comunic. Saúde Educ., 2005; 9(16):69-79.

13. Weeks JCet al. Patients' Expectations about Effects of Chemotherapy for Advanced Cancer. The N Engl J Med2012; 367:1616-1625.

14. Rhoades DR, McFarland KF, Finch WH, Johson AO. Speaking and interruptions during primary care office visits. Family Medicine 2001;33(7):528-532.

\section{CONTRIBUIÇÃO DOS AUTORES}

Os autores Paula de Oliveira Montandon Hokama e Newton Key Hokama foram responsáveis pela concepção, delineamento e aplicação da metodologia proposta, assim pela redação do manuscrito. $\mathrm{O}$ autor Nildo Alves Batista foi responsável pela revisão crítica relevante do material intelectual do manuscrito.

\section{CONFLITO DE INTERESSES}

Os autores declaram não haver conflito de interesse de ordem pessoal, comercial, acadêmica, política ou financeira na produção do manuscrito.

\section{ENDEREÇO PARA CORRESPONDÊNCIA}

Paula de Oliveira Montandon Hokama

e-mail:paula.hokama@unesp.br

Faculdade de Medicina de Botucatu - Unesp

Departamento de Clínica Médica

Distrito de Rubião Júnior - Botucatu - SP

CEP: 18618-000 